\title{
Bipolar Transurethral Prostate Resection: A Study of 112 Cases
}

\author{
Cyril Kamadjou ${ }^{1,2}$, Jerry Kuitche1, Divine Enorou Eyongeta ${ }^{3}$, Achille Mbassi ${ }^{4}$, Fru Angwafor ${ }^{5}$ \\ ${ }^{1}$ Centre Medico-Chirugical d'urologie, Douala, Cameroon \\ ${ }^{2}$ Department of Surgery and Specialties, Faculty of Medicine and Pharmaceutical Sciences, University of Douala, Douala, Cameroon \\ ${ }^{3}$ Department of Surgery, Faculty of Health Sciences, University of Buea, Buea, Cameroon \\ ${ }^{4}$ Yaounde Central Hospital, Yaoundé, Cameroon \\ ${ }^{5}$ Coordinator Urology Residency Program, Faculty of Medicine and Biomedical Sciences, University of Yaoundé, Yaoundé, Cameroon \\ Email: cyrkamadjou@yahoo.fr
}

How to cite this paper: Kamadjou, C., Kuitche, J., Eyongeta, D.E., Mbassi, A. and Angwafor, F. (2022) Bipolar Transurethral Prostate Resection: A Study of 112 Cases. Open Journal of Urology, 12, 117-128. https://doi.org/10.4236/oju.2022.122012

Received: January 6, 2022

Accepted: February 14, 2022

Published: February 17, 2022

Copyright (c) 2022 by author(s) and Scientific Research Publishing Inc. This work is licensed under the Creative Commons Attribution International License (CC BY 4.0).

http://creativecommons.org/licenses/by/4.0/

(c) (i) Open Access

\begin{abstract}
Background: With the advancement of technology, prostate resection can be performed nowadays using endoscopic techniques, which include monopolar and bipolar transurethral prostate resection. This study aimed to evaluate the results of bipolar transurethral prostate resection in a single urology center in Cameroon. Materials and Methods: This was a retrospective study carried out over two years (2015-2017) involving 112 patients with symptomatic prostate diseases who underwent transurethral prostate resection with the help of a bipolar Olympus generator. Results: The ages of the participants ranged from 44 years to 85 years, with a mean age of $64.41 \pm 9.5$ years. Fifty-six (50\%) patients presented with only obstructive symptoms, five $(4.46 \%)$ had only irritative symptoms, twenty (17.86\%) presented with both obstructive and irritative symptoms, eight (7.14\%) presented with macroscopic hematuria, seven (6.25\%) with urinary tract infections, and sixteen (14.29\%) with acute urinary retention. Digital rectal examination was unremarkable in $74(66.07 \%)$ findings and was positive in $38(33.93 \%)$ patients. The median prostate diameter was 70 [59 - 86.5] $\mathrm{mm}$. The mean preoperative IPSS was $24.46 \pm 5.68$. The mean surgery duration was $77.61 \pm 23.87$ minutes. The mean volume of irrigation fluid used during surgery was $24.84 \pm 6.40 \mathrm{ml}$. The differences between the preoperative and postoperative mean IPPS score, maximum urine flow rate, and quality of life were statistically significant (all $\mathrm{P}<0.001)$. Only 4 (3.57\%) of the study participants experienced postoperative complications. Conclusion: Bipolar transurethral prostate resection is a viable alternative to open surgery or laparoscopic surgery for large prostate glands. This technique is also associated with a reduction in prostate-related morbidity.
\end{abstract}




\section{Keywords}

Bipolar Transurethral Prostate Resection, Prostatism, Quality of Life, Irrigation Fluid, Large Prostate Glands

\section{Introduction}

The prostate is a gland of the male reproductive system. It is located directly in front of the rectum and just below the urinary bladder. Its unique location makes it possible for the gland to be palpated during digital rectal examinations. The prostate measures approximately $3 \mathrm{~cm} \times 3 \mathrm{~cm} \times 5 \mathrm{~cm}$ and has an approximate volume of $25 \mathrm{ml}$ [1]. Like every other organ, the prostate has its pathological conditions, the most common of which are benign prostatic hypertrophy, prostate cancer, and chronic prostatitis [2]. There are some symptoms that are characteristic of prostate pathologies, the most common of which are lower urinary tract symptoms (LUTS), which are mainly obstructive (voiding) symptoms and irritative (storage) symptoms. Obstructive symptoms include urinary retention, weak stream, interrupted stream, hesitancy, straining, prolonged micturition, incomplete bladder voiding, and dribbling. Irritative symptoms include frequency, urgency, urge incontinence, and nocturia [3]. Prostate pathology is also characterized by an enlargement of the prostate gland (which can be perceived during digital rectal examinations) and sexual dysfunction (which could be linked not only to the prostate diseases but to its different treatment modalities such as medical treatment, radiotherapy, and surgery) [4]. Transrectal ultrasonography is the most commonly used imaging modality for the prostate [5]. Prostate pathologies also have biological markers, the most common of which is the prostate-specific antigen (PSA) [6]. Surgical techniques for the management of patients with prostatism include transurethral resection of the prostate (TURP) and endoscopic enucleation of the prostate [7], with TURP being the gold standard and most commonly used surgical technique [8]. However, new minimally invasive surgical techniques, such as the bipolar modification of TURP (B-TURP) have been developed [2]. B-TURP has been reported to offer the theoretical advantage of providing more time to perform resection (which allows for the resection of larger prostate glands) and controlling hemostasis without compromising safety [9]. The improved hemostasis with B-TURP can be explained by the cut-and-seal effect [10]. B-TURP has also been reported to have the advantages of lesser clot retention, greater efficacy, and improvement in the transurethral resection (TUR) syndrome over monopolar TURP (M-TURP) [11]. Given the context of Cameroonian medical practice (low-resource settings and rare practice of endoscopic surgery), techniques such as B-TURP are rarely used. Hence, this study aimed to evaluate the results of B-TURP in a single urology center in Cameroon.

\section{Patients and Methods}

This was a retrospective study carried out from 2015 to 2017 at the Centre me- 
dico-chirugicale d urologie de Douala. We consulted the clinical records of patients with symptomatic prostate pathologies who underwent transurethral prostate resection with the help of a bipolar Olympus generator. We included all patients who underwent B-TURP at our center from 2015 to 2017 and excluded those with incomplete clinical records. In the end, we recruited a total of $112 \mathrm{pa}-$ tients in this study. The data we obtained from the participants' clinical records included patients' age, histological classification (for cases of malignancy), initial clinical presentation, digital rectal examination findings, patients' initial prostate-specific antigen (PSA) levels, patients' prostate diameter on transrectal ultrasound (TRUS), initial and final international prostate symptom score (IPSS), patients' initial and final quality of life, patients' initial and final maximum urine flow rate (Qmax), indication for the surgery, surgery duration, the amount of fluid used during surgery, duration of the indwelling catheter (days), duration of postoperative complications, and postoperative complications. The digital rectal examination findings were unremarkable if there was no suspicion of prostate cancer and positive if prostate cancer was suspected upon palpation of the prostate. The IPSS score was assessed using a standardized questionnaire (IPSS questionnaire) that contains seven questions on the obstructive and irritative symptoms of prostatism, with each question scored from 0 to 5 , with 0 indicating the complete absence of the symptom and 5 indicating the constant presence of the symptom (Figure 1). This questionnaire also contains a question on the patient's quality of life, which is scored from 0 to 6 , with 0 indicating the best possible quality of life and 6 indicating the worst possible quality of life. With this questionnaire, the total score ranges from 0 to 35 , with $0-7$ being mildly symptomatic, 8 - 19 moderately symptomatic, and 20 - 35 being severely symptomatic. Surgery is usually indicated for severely symptomatic patients. Uroflowmetry was also performed in all patients before and after surgery to evaluate the Qmax. A Qmax of $>15 \mathrm{ml} / \mathrm{s}$ is considered normal while a Qmax of $<10 \mathrm{ml} / \mathrm{s}$ is considered abnormal [12].

Before surgery, all the patients consulted an anesthetist and did certain laboratory tests. These included a complete blood count, blood urea, serum creatinine, prothrombin time, kaolin-cephalin coagulation time, and urinalysis. This was to ensure that the patients had satisfactory blood cell counts, hemoglobin levels, kidney function indexes, and sterile urine before the surgery since a urinary tract infection of any kind is a contraindication to this mini-invasive procedure.

The patients underwent transurethral prostate resection with the help of a bipolar Olympus generator. All the interventions were carried out by the same urologist. The data collected from the patients' clinical records were entered into Microsoft Excel 2016 and then exported to Epi info 7 for statistical analysis. This study was approved by the institutional review board of the Faculty of Medicine and Pharmaceutical Sciences (FMPS) of the University of Douala and by the ethical committee of the Centre medico-chirugicale d urologie in Douala, Cameroon. The requirement for patients' informed consent was waived due to the 
retrospective nature of the study. Continuous variables were presented as mean values and standard deviations for normally distributed data and as median values with interquartile ranges for data with skewed distributions. The independent samples t-test was used to compare between normally distributed continuous variables while the Mann-Whitney $U$ test was used to compare continuous variables with skewed data distributions. The chi-square test and the Fisher exact test were used to compare categorical variables. Values of $\mathrm{P}<0.05$ were considered statistically significant.

\section{Results}

The ages of the participants ranged from 44 years to 85 years, with a mean age of $64.41 \pm 9.5$ years. Out of the 112 patients, $73(65.18 \%)$ had benign prostatic hypertrophy (BPH) while $39(34.82 \%)$ had prostate cancer. Fifty-six (50\%) patients presented with only obstructive symptoms, five (4.46\%) had only irritative symptoms, twenty (17.86\%) presented with both obstructive and irritative symptoms, eight (7.14\%) presented with macroscopic hematuria, seven $(6.25 \%)$ with urinary tract infections, and sixteen (14.29\%) with acute urinary retention. Digital rectal examination was unremarkable in 74 (66.07\%) findings and was positive in 38 (33.93\%) patients. The preoperative quality of life score was 3 in 14 (12.5\%) patients, 4 in $30(26.79 \%)$ patients, 5 in 40 (35.71\%) patients, and 6 in 28 (25\%) patients. The preoperative IPSS scores ranged from 12 to 35, with a mean score of $24.46 \pm 5.68$. The diameters of the prostate gland ranged from $30 \mathrm{~mm}$ to $150 \mathrm{~mm}$, with a median value of 70 [59 - 86.5] mm. A total of $37(33.04 \%)$ had diameters of $30-60 \mathrm{~mm}, 52$ (46.43\%) had diameters of $61-90 \mathrm{~mm}, 20(17.86 \%)$ had diameters of $91-120 \mathrm{~mm}$, while 3 (2.67\%) had diameters of more than 120 $\mathrm{mm}$. The serum PSA levels of the participants ranged from $1.5 \mathrm{ng} / \mathrm{ml}$ to 4964 $\mathrm{ng} / \mathrm{ml}$, with a median value of 15 [7 - 58] ng/ml. Seventy-three $(65.18 \%)$ of participants had serum PSA levels of 0 - $20 \mathrm{ng} / \mathrm{ml}, 25$ (22.32\%) of them had levels of $20-100 \mathrm{ng} / \mathrm{ml}$, and 14 (12.5\%) participants had PSA levels of more than 100 $\mathrm{ng} / \mathrm{ml}$. The preoperative Qmax ranged from $4 \mathrm{ml} / \mathrm{s}$ to $15 \mathrm{ml} / \mathrm{s}$, with a mean value of $9.85 \pm 3.03 \mathrm{ml} / \mathrm{min}$. The preoperative QoL score ranged from 3 to 6 , with a mean score of $4.73 \pm 0.98$. The indication for surgery was failure of medical treatment in 61 (54.46\%) participants, recurrent urinary tract infections (UTIs) in $3(2.68 \%)$ participants, acute urinary retention in 4 (3.57\%) participants, prostatic adenocarcinoma in $31(27.68 \%)$ participants, and it was the patient's choice in 13 (11.61\%) participants. The preoperative profiles of the study participants are presented in Table 1.

The duration of the surgery ranged from 15 minutes to 150 minutes, with a mean duration of $77.61 \pm 23.87$ minutes. The volume of irrigation fluid used during the surgery ranged from $15 \mathrm{ml}$ to $45 \mathrm{ml}$, with a mean volume of $24.84 \pm$ $6.40 \mathrm{ml}$. The number of days of hospitalization was 2 in 29 (25.89\%) participants and 3 in $83(74.11 \%)$ participants. The average number of days of hospitalization was 2.74 days. Twenty-nine $(25.89 \%)$ patients were hospitalized for two days 


\section{International Prostate Symptom Score (I-PSS)}

Patient Name:

Date of birth:

Date completed

\begin{tabular}{|c|c|c|c|c|c|c|c|}
\hline $\begin{array}{c}\text { In the past } \\
\text { month: }\end{array}$ & $\begin{array}{l}\text { Not at } \\
\text { All }\end{array}$ & $\begin{array}{l}\text { Less than } \\
1 \text { in } 5 \\
\text { Times }\end{array}$ & $\begin{array}{l}\text { Less than } \\
\text { Half the } \\
\text { Time }\end{array}$ & $\begin{array}{c}\text { About } \\
\text { Half } \\
\text { the } \\
\text { Time }\end{array}$ & $\begin{array}{c}\text { More } \\
\text { than Half } \\
\text { the Time }\end{array}$ & $\begin{array}{l}\text { Almost } \\
\text { Always }\end{array}$ & $\begin{array}{l}\text { Your } \\
\text { score }\end{array}$ \\
\hline $\begin{array}{l}\text { 1. Incomplete Emptying } \\
\text { How often have you had the } \\
\text { sensation of not emptying } \\
\text { your bladder? }\end{array}$ & 0 & 1 & 2 & 3 & 4 & 5 & \\
\hline $\begin{array}{l}\text { 2. Frequency } \\
\text { How often have you had to } \\
\text { urinate less than every two } \\
\text { hours? }\end{array}$ & 0 & 1 & 2 & 3 & 4 & 5 & \\
\hline $\begin{array}{l}\text { 3. Intermittency } \\
\text { How often have you found } \\
\text { you stopped and started again } \\
\text { several times when you } \\
\text { urinated? }\end{array}$ & 0 & 1 & 2 & 3 & 4 & 5 & \\
\hline $\begin{array}{l}\text { 4. Urgency } \\
\text { How often have you found it } \\
\text { difficult to postpone } \\
\text { urination? }\end{array}$ & 0 & 1 & 2 & 3 & 4 & 5 & \\
\hline $\begin{array}{l}\text { 5. Weak Stream } \\
\text { How often have you had a } \\
\text { weak urinary stream? }\end{array}$ & 0 & 1 & 2 & 3 & 4 & 5 & \\
\hline \multirow{2}{*}{$\begin{array}{l}\text { 6. Straining } \\
\text { How often have you had to } \\
\text { strain to start urination? }\end{array}$} & 0 & 1 & 2 & 3 & 4 & 5 & \\
\hline & None & 1 Time & 2 Times & 3 Times & 4 Times & 5 Times & \\
\hline $\begin{array}{l}\text { 7. Nocturia } \\
\text { How many times did you } \\
\text { typically get up at night to } \\
\text { urinate? }\end{array}$ & 0 & 1 & 2 & 3 & 4 & 5 & \\
\hline $\begin{array}{l}\text { Total I-PSS } \\
\text { Score }\end{array}$ & & & & & & & \\
\hline
\end{tabular}

Score: 1-7: Mild 8-19: Moderate 20-35: Severe

\begin{tabular}{|l|c|c|c|c|c|c|c|}
\hline $\begin{array}{l}\text { Quality of Life Due to } \\
\text { Urinary Symptoms }\end{array}$ & Delighted & Pleased & $\begin{array}{c}\text { Mostly } \\
\text { Satisfied }\end{array}$ & Mixed & $\begin{array}{c}\text { Mostly } \\
\text { Dissatisfied }\end{array}$ & Unhappy & Terrible \\
\hline $\begin{array}{l}\text { If you were to spend the rest of } \\
\text { your life with your urinary } \\
\text { condition just the way it is now, } \\
\text { how would you feel about that? }\end{array}$ & $\mathbf{0}$ & $\mathbf{1}$ & $\mathbf{2}$ & $\mathbf{3}$ & $\mathbf{4}$ & $\mathbf{5}$ & $\mathbf{6}$ \\
\hline
\end{tabular}

Figure 1. The IPSS questionnaire. 
Table 1. Preoperative profiles of the study participants.

\begin{tabular}{cc}
\hline Variable & $\mathrm{N}(\%)$ \\
\hline Age (years) & $12(10.71)$ \\
$40-50$ & $29(25.89)$ \\
$51-60$ & $42(37.50)$ \\
$61-70$ & $25(22.32)$ \\
$71-80$ & $4(3.57)$ \\
$>80$ & \\
Pathology & $73(65.18)$ \\
Benign prostatic hypertrophy & $39(34.82)$ \\
Prostate cancer & \\
Symptoms & $56(50)$ \\
Obstructive symptoms only & $5(4.46)$ \\
Irritative symptoms only & $20(17.86)$ \\
Obstructive and irritative symptoms & $8(7.14)$ \\
Macroscopic hematuria & $7(6.25)$ \\
Urinary tract infections & $16(14.29)$ \\
Acute urinary retention &
\end{tabular}

\section{Digital rectal examination}

Unremarkable

Positive

QoL score

$$
3
$$$$
4
$$$$
5
$$

6

\section{IPSS score}

$$
\begin{gathered}
0-7 \\
8-19 \\
20-35
\end{gathered}
$$

Prostate diameter $(\mathrm{mm})$

$$
\begin{gathered}
30-60 \\
61-90 \\
91-120
\end{gathered}
$$$$
>120
$$

\section{Serum PSA level (ng/ml)}

$\begin{array}{cc}0-20 & 73(65.18) \\ 21-100 & 25(22.32) \\ >100 & 14(12.50)\end{array}$

$74(66.07)$

38 (33.93)

$14(12.50)$

30 (26.79)

40 (35.71)

$28(25.00)$

$$
0(00)
$$

29 (25.89)

83 (74.11)

37 (33.04)

$52(46.43)$

20 917.86)

$14(12.50)$

$14(12.50)$ 


\begin{tabular}{cc}
\hline Qmax $(\mathrm{ml} / \mathrm{s})$ & \\
$<10$ & $49(43.75)$ \\
$10-15$ & $63(56.25)$ \\
$>15$ & 0 \\
\hline Indication for surgery & $61(54.46)$ \\
Treatment failure & $31(27.68 \%)$ \\
Prostatic adenocarcinoma & $13(11.61 \%)$ \\
Choice & $4(3.57 \%)$ \\
Acute urinary retention & $3(2.68 \%)$ \\
Recurrent urinary tract infections
\end{tabular}

while 83 (74.11\%) were hospitalized for three days. The duration of the indwelling catheter ranged from 1 day to 5 days, with a mean duration of $2.60 \pm 1.28$ days. Most of our study participants (108, 97.30\%) experienced no postoperative complications. Only 4 (3.57\%) of the study participants experienced postoperative complications. Of these four, two had acute urinary retention, one had a urinary tract infection, and another one experienced multiple clot formation. All the patients with complications were managed within the next few days. In each patient with acute urinary retention, an indwelling urinary catheter was left in place for five days and removed thereafter. The patient with a urinary tract infection was treated using intravenous carbapenem for seven days during which an indwelling urinary catheter was left in place. The catheter was removed thereafter and the infection was resolved. The patient with multiple clot formation underwent surgical removal of these clots under spinal anesthesia, during which hemostasis of the bleeding vessel responsible for clot formation was performed through electrocautery. After the repeat surgery, an indwelling three-way catheter was left in place for two days. All postoperative complications were managed within a week of their occurrence. The postoperative Qmax ranged from $15 \mathrm{ml} / \mathrm{s}$ to $32 \mathrm{ml} / \mathrm{s}$, with a mean value of $22.46 \pm 4.69 \mathrm{ml} / \mathrm{min}$. The difference between the preoperative and postoperative Qmax values was statistically significant $(\mathrm{P}<$ $0.001)$. The postoperative QoL score ranged from 0 to 2, with an average score of 0.56 . There was a significant improvement in the quality of life $(\mathrm{P}<0.001)$. The postoperative IPSS scores ranged from 2 to 15 , with a mean value of $7.85 \pm 3.10$. The difference between the preoperative and postoperative mean IPPS scores was statistically significant $(P<0.001)$. The intraoperative and postoperative features of the study participants are presented in Table 2.

\section{Discussion}

This study aimed to evaluate the results of bipolar transurethral prostate resection in a single urology center in Cameroon. We recruited a total of 112 patients with symptomatic prostate pathologies who underwent transurethral prostate 
Table 2. Intraoperative and postoperative characteristics of the study participants.

\begin{tabular}{cc}
\hline Variable & $\mathrm{N}(\%)$ \\
\hline Surgery duration (minutes) & \\
$0-60$ & $36(32.14)$ \\
$61-120$ & $74(66.07)$ \\
$>120$ & $2(1.79)$
\end{tabular}

Volume of fluid used (ml)

$\begin{array}{cc}15-20 & 24(21.43) \\ 21-30 & 75(66.96) \\ 31-40 & 10(8.93) \\ >40 & 3(2.68)\end{array}$

Duration of hospitalization (days)

$29(25.89)$

$3 \quad 83(74.11)$

Duration of indwelling catheter (days)

$1 \quad 5(4.46)$

$283(74.11)$

$5 \quad 24(21.43)$

Complications

None $108(97.30)$

Acute urinary retention 2 (1.79)

Urinary tract infection $\quad 1(0.89)$

Clot formation $\quad 1(0.89)$

IPSS score

$0-7 \quad 57(50.89)$

$8-19 \quad 55(49.11)$

$20-35 \quad 0(00)$

Quality of life

$0 \quad 52(46.43)$

$157(50.89)$

$23(2.68)$

$\mathrm{Q} \max (\mathrm{ml} / \mathrm{s})$

$>15 \quad 112(100)$

resection with the help of a bipolar Olympus generator. The mean age of our study participants was $64.41 \pm 9.5$ years, which is similar to the $68.7 \pm 7.1$ reported by Pougla et al. in 2021 [13]. This similarity in the mean age can be explained by the fact that symptoms of prostatism, especially severe symptoms, usually occur in men of this age group. Obstructive symptoms were the main 
presenting complaints of our study participants, which was expected since these symptoms are usually the first to occur and are more common in patients with prostatism, as was reported in the study by Liu et al. in 2003 [14]. The mean surgery duration was $77.61 \pm 23.87$ minutes, which is higher than the $55.71 \pm$ 13.46 reported by Pougla et al. in 2021 [13]. This difference is probably because the prostate glands of our patients were relatively larger (median prostate diameter: 70 [59 - 86.5] $\mathrm{mm}$, which corresponds to a median prostate volume of approximately $179.67 \mathrm{cc}$ ) than those in the study by Pougla et al. (they reported a mean prostate volume of $51 \pm 9.85 \mathrm{cc}$ in the B-TURP group), which means that we had more prostate tissue to resect than they did. Thanks to the experience we have acquired over the years, we can afford to take on such larger prostate glands during the B-TURP procedure, which comes with an increase in the surgery duration. The mean volume of irrigation fluid used during surgery was $24.84 \pm 6.40 \mathrm{ml}$, which is lower than the $68.7 \mathrm{ml}$ reported by Jeje et al. in 2021 [15]. This difference can be explained by the fact that, unlike Jeje et al. who carried out monopolar resection, we did not use a suprapubic trocar in our procedure. This means we did not continually recycle the fluid in the bladder during our study. Furthermore, the flow of saline into the bladder during our B-TURP procedure was intermittent and not continuous. Each time there was overt bleeding, a small amount of fluid was irrigated to clear off the blood from the surgeon's visual field and continue the procedure. Since the intraoperative blood loss during our surgical procedure was minimal, we did not need to frequently clear the surgeon's visual field using irrigation fluid, which further explains the small volume of this fluid used during our surgical procedures. The average duration of hospitalization in our study was 2.74 days, which is higher than the 32 hours reported by Mertziotis et al. in 2015 [16]. This difference is mainly because, in the Cameroonian context, patients are not yet used to endoscopic procedures. As such, they are skeptical about getting discharged so soon after the procedure and prefer to stay for longer in the hospital. We are positive that as the years go by and endoscopic procedures become more common in our resource-limited setting, patients will feel more comfortable going home within 24 hours of the end of mini-invasive surgical procedures. The prevalence of postoperative complications in our study was $3.57 \%$, which is approximately double the rate reported by Sugihara et al. in 2012 [17]. This difference could be explained by the fact that we worked on relatively larger prostate glands, which increased the duration of our interventions. The longer duration of our interventions predisposed our patients to a higher rate of complications than is reported in the literature. The most common postoperative complication in our study was acute urinary retention, which accounted for $50 \%$ of all complications. This could be caused by incomplete resection of the prostate, blood clots that end up blocking the flow of urine, or pieces of tissue from the resected prostate that block the bladder outlet [18]. The urinary retention could also be due to underactive bladders caused by the prolonged presence of urinary catheters in the 
bladder after the intervention [19]. Of the two cases of urinary retention that occurred as postoperative complications, one was caused by underactive bladder while the other was due to bladder outlet obstruction by pieces of resected prostate tissue. That notwithstanding, the complications we observed in our study were easily managed and the patients did not have to spend much time in the hospital. We observed significant improvements in the IPSS score, Qmax, and quality of life with the B-TURP technique, which is similar to the findings of Mertziotis et al. in 2015 [16]. This finding confirms the efficacy of B-TURP and further explains why it is currently the gold standard technique for prostate resection. However, our study had a few limitations. First, the retrospective study design means there was recall bias involved. Second, we recruited only patients that underwent B-TURP with no patients that underwent M-TURP. This means that we could not demonstrate via comparisons that B-TURP is better than M-TURP in this study. We suggest that a comparative prospective study between M-TURP and B-TURP be carried out in the future.

\section{Conclusion}

Endoscopic resection of the prostate is the gold standard technique for prostate resection in patients with prostatism. There are different endoscopic techniques, including monopolar resection and bipolar resection. Bipolar resection has the advantage of enabling surgeons to perform resections for much larger prostate glands since the procedure can last longer, mainly thanks to the better hemostasis and reduced occurrence of the TUR syndrome associated with this technique. The bipolar technique is also associated with a reduction in prostate-related morbidity.

\section{Acknowledgements}

The authors thank Health Search Association for critically reviewing the manuscript.

\section{Availability of Data and Materials}

The data analyzed in this study are available from the corresponding author upon reasonable request.

\section{Funding}

The authors did not receive any funding for this study.

\section{Ethics Statement}

Ethical approval was obtained from the institutional review board of the Faculty of Medicine and Pharmaceutical Sciences and the ethics committee of the Centre medico-chirugicale d urologie in Douala, Cameroon. The requirement for informed consent was waived due to the retrospective nature of the study. 


\section{Conflicts of Interest}

The authors have no conflicting interests to declare.

\section{References}

[1] Mitterberger, M., Horninger, W., Aigner, F., Pinggera, G.M., Steppan, I., Rehder, P., et al. (2010) Ultrasound of the Prostate. Cancer Imaging, 10, 40-48. https://doi.org/10.1102/1470-7330.2010.0004

[2] Xia, S.-J., Cui, D. and Jiang, Q. (2012) An Overview of Prostate Diseases and Their Characteristics Specific to Asian Men. Asian Journal of Andrology, 14, 458-464. https://doi.org/10.1038/aja.2010.137

[3] Lepor, H. (2005) Pathophysiology of Lower Urinary Tract Symptoms in the Aging Male Population. Reviews in Urology, 7, S3-S11.

[4] Kim, S.W. (2011) Prostatic Disease and Sexual Dysfunction. Korean Journal of Urology, 52, 373-378. https://doi.org/10.4111/kju.2011.52.6.373

[5] Turkbey, B., Pinto, P.A. and Choyke, P.L. (2009) Imaging Techniques for Prostate Cancer: Implications for Focal Therapy. Nature Reviews Urology, 6, 191-203. https://doi.org/10.1038/nrurol.2009.27

[6] Gretzer, M.B. and Partin, A.W. (2003) PSA Markers in Prostate Cancer Detection. Urologic Clinics of North America, 30, 677-686. https://doi.org/10.1016/S0094-0143(03)00057-0

[7] Miernik, A. and Gratzke, C. (2020) Current Treatment for Benign Prostatic Hyperplasia. Deutsches Ärzteblatt International, 117, 843-854. https://doi.org/10.3238/arztebl.2020.0843

[8] Smith, R.D. and Patel, A. (2011) Transurethral Resection of the Prostate Revisited and Updated. Current Opinion in Urology, 21, 36-41. https://doi.org/10.1097/MOU.0b013e3283411455

[9] Hueber, P.-A., Al-Asker, A. and Zorn, K.C. (2011) Monopolar vs. Bipolar TURP: Assessing Their Clinical Advantages. Canadian Urological Association Journal, 5, 390-391. https://doi.org/10.5489/cuaj.11263

[10] Madduri, V.K.S., Bera, M. and Pal, D.K. (2016) Monopolar versus Bipolar Transurethral Resection of Prostate for Benign Prostatic Hyperplasia: Operative Outcomes and Surgeon Preferences, a Real-World Scenario. Urology Annals, 8, 291-296. https://doi.org/10.4103/0974-7796.184900

[11] Tang, Y., Li, J., Pu, C., Bai, Y., Yuan, H., Wei, Q., et al. (2014) Bipolar Transurethral Resection versus Monopolar Transurethral Resection for Benign Prostatic Hypertrophy: A Systematic Review and Meta-Analysis. Journal of Endourology, 28, 1107-1114. https://doi.org/10.1089/end.2014.0188

[12] Mamoulakis, C. and Oelke, M. (2018) Chapter 6. Diagnostic Work-Up of LUTS/BPH: From Standard to New Perspectives. In: Morgia, G. and Russo, G.I., Eds., Lower Urinary Tract Symptoms and Benign Prostatic Hyperplasia, Academic Press, Cambridge, 113-133. https://doi.org/10.1016/B978-0-12-811397-4.00006-8 https://www.sciencedirect.com/science/article/pii/B9780128113974000068

[13] Pogula, V. and Galeti, E. (2021) A Prospective Comparative Study on the Operative Outcomes between Monopolar Versus Bipolar Transurethral Resection of Prostate for Benign Prostatic Hyperplasia: An Institutional Experience. Asian Journal of Medical Sciences, 12, 125-132. https://doi.org/10.3126/ajms.v12i11.38923

[14] Liu, C.-C., Huang, S.-P., Chou, Y.-H., Wang, C.-J. and Huang, C.-H. (2003) Current Indications for Transurethral Resection of the Prostate and Associated Complica- 
tions. The Kaohsiung Journal of Medical Sciences, 19, 49-54. https://doi.org/10.1016/S1607-551X(09)70448-6

[15] Jeje, E.A., Alabi, T.O., Ojewola, R.W., Ogunjimi, M.A., Tijani, K.H. and Asiyanbi, G.K. (2021) Monopolar Transurethral Resection of the Prostate Using Water as the Irrigation Fluid: Our Initial Experience. Nigerian Postgraduate Medical Journal, 28, 175-180. https://doi.org/10.4103/npmj.npmj 50221

[16] Mertziotis, N., Kozyrakis, D., Kyratsas, C. and Konandreas, A. (2015) A Prospective Study of Bipolar Transurethral Resection of Prostate Comparing the Efficiency and Safety of the Method in Large and Small Adenomas. Advances in Urology, 2015, Article ID: 251879. https://doi.org/10.1155/2015/251879

[17] Sugihara, T., Yasunaga, H., Horiguchi, H., Nakamura, M., Nishimatsu, H., Kume, H., et al. (2012) In-Hospital Outcomes and Cost Assessment between Bipolar Versus Monopolar Transurethral Resection of the Prostate. Journal of Endourology, 26, 1053. https://doi.org/10.1089/end.2011.0592

[18] Ketabchi, A.A., Ketabchi, M. and Barkam, M. (2013) The Effect of Modified TURP (M-TURP) in Intra and Postoperative Complications. Nephro-Urology Monthly, 5, 758-761. https://doi.org/10.5812/numonthly.6607

[19] Miyazato, M., Yoshimura, N. and Chancellor, M.B. (2013) The Other Bladder Syndrome: Underactive Bladder. Reviews in Urology, 15, 11-22. 